\title{
Epidemiology of accidental home poisoning in Riyadh (Saudi Arabia)
}

\author{
AWAD H MAHDI, SALAH ALI TAHA, AND M R AL RIFAI \\ From the Department of Paediatrics, King Khalid Hospital, Riyadh, Saudi Arabia
}

SUMMARY In a prospective study on 178 cases of accidental home poisoning admitted to the main children's hospital in Riyadh poisoning was found to account for $5.6 \%$ of the total annual admissions-greater than any other developing country and approaching Western proportions. The commonest ages were between 1 and 5 years. Drugs accounted for $52 \%$ of cases and household products for $46 \%$. This picture also differs from the pattern of poisoning in developing countries and is more akin to that of industrialised countries. The most important factors in aetiology, besides the age of the patient and the underprivileged social class, were the abundance of drugs and household chemicals in the Saudi home, none of them in child proof containers; inappropriate storage; and lack of supervision of children. Cultural factors also contributed. The frequency of poisoning in childhood may be decreased in the long run by improved housing, socioeconomic status, and education. The place and methods of health education, also a long term objective, is discussed. For immediate primary prevention two important legislative measures are proposed: (1) provision of childproof containers of drugs and other chemicals used in the home and (2) banning of over the counter sales of drugs. For more accurate epidemiological data collection, and thereby better preventative planning, a national register of accidental poisoning and other accidents is recommended. Poison information centres are also deemed necessary.

It is well established that morbidity of accidental poisoning in children under 5 years of age is high and is increasing in Western countries. ${ }^{1-5}$ What is not equally recognised is that estimates from some developing countries show that accidents are of the same magnitude as they are in industrialised countries. ${ }^{6}$ Indeed some reports state that accidents are increasing and are tending to replace classic causes of death. ${ }^{\mathrm{r}}$ ?

There is no published report on the subject from Saudi Arabia showing the nature and extent of this problem. The present paper explores only one aspect of childhood accidents-accidental home poisoning-through a prospective hospital based study. The objectives are to delineate the aetiological and ecological factors responsible for these accidents in Riyadh with a view to suggesting preventative actions relevant to this society.

\section{Material and methods}

The study was conducted between August 1981 and October 1982 on two days a week on all patients admitted to the casulaty department and wards of the children's hospital in Riyadh. During that period 3360 patients were admitted under our care. Of these, $178(5 \cdot 3 \%)$ patients aged 6 months to 7 years had ingested some form of poisonous substance at home.

After a quick history, an initial examination, and management of the patient, one of the parents, usually the mother, was interviewed for further details. Data were collected on a structured and precoded questionnaire. Information was sought on the child, the poison, its container, and the circumstances in which it was taken. Information was also obtained on the child's home as defined by Whittington, ${ }^{4}$ storage pattern, degree of supervision, and family background.

Identification of the offending product depended on the description of the parents and inspection of the product or the label on the container. A toxicology laboratory not being available, analytical investigations for confirmation were rarely done.

In 72 patients who showed symptoms and signs or when circumstantial evidence of ingestion of poison were considered very strong the stomach was evacuated. This did not include those with kerosine 
or corrosive poisoning. The procedure was done immediately on arrival; sometimes four hours or more after the accidents, particularly if salicylates or lomotil were implicated. ${ }^{8}$ Otherwise further treatment depended on the cause and course of events.

Most patients were kept under observation for at least 24 hours especially when kerosine, iron, salicylates, or sedatives were incriminated or when the poison remained unidentified.

None of the patients died.

\section{Results}

Of the 178 children studied, 93 were boys and 85 were girls, a male to female ratio of 1.10:1.0. The mean age was 27 months (range 6 months to 7 years): 170 patients were between 1 and 5 years. On 20 occasions more than one child was affected in the same episode. Twenty three children, 16 boys and seven girls, had ingested poison on a previous occasion-" "poison repeaters."

Ninety three of the children were poisoned by drugs and 82 by domestic products, particularly kerosine (table 1). Organophosphrous insecticides and pesticides were not encountered.

In only $5 \%$ of cases (table 2 ) were drugs that had been prescribed for the child implicated. None of the families had a specifically located medicine cupboard, and most mothers were ignorant of the potential toxicity of drugs, let alone domestic products.

The peak hours of poisoning were between $11 \mathrm{am}$ and $400 \mathrm{pm}$ when the housewife is usually very busy. Most episodes occurred in the family's residence with 61 cases in the living cum bedroom; 42 in the kitchen, where the refrigerator is a favourite place for storing medicines; 13 in the bathroom; and 34 elsewhere. There were 11 accidents in relative's quarters and 17 in the area surrounding the home that is out of bounds to the Saudi mother. Table 3 shows the storage patterns. In all instances chemicals were inappropriately placed, cabinets, when present, were unlocked, and containers could easily be opened by a child.

Table 4 shows the mothers' activities and possible distraction at the time of the accident. Most mothers are not able to guard and protect the poisoned child who is left to his own devices. In $18 \%$ of cases supervision was delegated to an older sibling - also a child-and in $26(15 \%)$ cases poisoning occurred in the presence of an adult. For practical purposes, therefore, very few of the children in this study were effectively supervised.

After the accident no first aid was given by 135
Table 1 Substance taken by 178 children

\begin{tabular}{|c|c|c|c|}
\hline & & No & $\%$ \\
\hline $\begin{array}{l}\text { Pharmaceutical preparations: } \\
\text { Identified } \\
\text { Unidentified }\end{array}$ & $\begin{array}{l}75 \\
18\end{array}$ & 93 & 52 \\
\hline $\begin{array}{l}\text { Domestic fluids: } \\
\text { Hydrocarbons (kerosine 45, } \\
\text { petroleum 1, diesel oil 1) }\end{array}$ & 47 & 82 & 46 \\
\hline Turpentine, shampoo, polish, etc & 17 & & \\
\hline Chlorine bleach & 9 & & \\
\hline Detergents & 6 & & \\
\hline Sulphuric acid & 3 & & \\
\hline \multicolumn{4}{|l|}{ Poisonous plants } \\
\hline Datura (stramonium) & & 3 & 2 \\
\hline Totals & & 178 & 100 \\
\hline
\end{tabular}

Table 2 Owner of the suspected drug

\begin{tabular}{lrr}
\hline & No & $\%$ \\
\hline One of the parents & 55 & $59 \cdot 1$ \\
Another sibling & 21 & 22.6 \\
Relatives & 12 & 13.0 \\
The patient & 5 & $5 \cdot 3$ \\
Total & 93 & $100 \cdot 0$ \\
\hline
\end{tabular}

Table 3 Place of the poison containers

\begin{tabular}{lcc}
\hline & No & $\%$ \\
\hline Refrigerator & 54 & 30 \\
Unlocked kitchen or bathroom cupboards & 38 & 21 \\
Accessible store room & 44 & 25 \\
Indiscriminately in rooms or outside home & 42 & 24 \\
& 178 & 100 \\
\hline
\end{tabular}

Table 4 Mothers' activity at time of accident

\begin{tabular}{lccc}
\hline & No & $\%$ \\
\hline $\begin{array}{l}\text { Doing her household chores } \\
\text { In the kitchen }\end{array}$ & 59 & 121 & 68 \\
$\begin{array}{l}\text { Attending to a baby } \\
\text { Arranging bedrooms }\end{array}$ & 23 & & \\
$\begin{array}{l}\text { Asleep or attending } \\
\text { to herself. }\end{array}$ & 27 & & \\
$\begin{array}{l}\text { Visiting or entertaining friends } \\
\text { At work }\end{array}$ & & 18 & 10 \\
Other distractions & 32 & 18 & 4 \\
Totals & & 178 & 100 \\
\hline
\end{tabular}


Table 5 Distribution of stress factors

\begin{tabular}{|c|c|c|c|}
\hline & & No & $\%$ \\
\hline $\begin{array}{l}\text { Maternal unfitness } \\
\text { Physical illness } \\
\text { New pregnancy }\end{array}$ & $\begin{array}{c}26 \\
6\end{array}$ & 32 & 17.9 \\
\hline Financial difficulties & & 12 & $6 \cdot 7$ \\
\hline Recent home moves & & 10 & $5 \cdot 6$ \\
\hline $\begin{array}{l}\text { One parent family ( } 2 \text { deaths } \\
1 \text { divorce) }\end{array}$ & & 3 & 1.6 \\
\hline $\begin{array}{l}\text { Depression and anxiety } \\
\text { states }\end{array}$ & & 2 & $1 \cdot 1$ \\
\hline Subtotal with stress & & 59 & $33 \cdot 0$ \\
\hline No stress factors & & 119 & $67 \cdot 0$ \\
\hline Totals & & 178 & $100 \cdot 0$ \\
\hline
\end{tabular}

families but 43 attempted emesis by manual induction or by giving salt and water or alternatively tried to dilute the poison by drinks of milk or cooking oil. These manoeuvres could be appropriate or extremely misguided depending on the nature of the poison. ${ }^{910}$ The mean delay between poisoning and attendance at the casualty department was 90 minutes (SD 40 minutes, range 30 to 280 ).

Sixty seven (38\%) families lived in small flats and $54(30 \%)$ in detached houses in the poor quarters of Riyadh. The remaining 57 (32\%) lived in tents or tin or mud houses in the outskirts of the town. Only 15 (8\%) families had one child, the patient, living with them whereas the remainder of the dwellings accommodated seven or more members of the family. In $28(16 \%)$ cases more than one wife, each with her own children, shared the same accommodation.

Most families belonged to the equivalent of the British social classes IV and V. In $80 \%$ of cases the child's father had elementary education and the mother no formal education at all.

Stress factors were identified in 59 (33\%) families (table 5). The major stress factor turned out to be maternal physical illness or pregnancy. One parent homes and psychiatric illness were not conspicuous. Ten of the 23 poison repeaters $(5.6 \%$ of the total number of children in this study) came from these affected families.

\section{Discussion}

Though the population of Riyadh is well defined, nothing is known of the morbidity and mortality rates of accidental poisoning per unit population of children, since neither a town, regional, nor national register of these accidents exists. In such circumstances admission to casualty departments and hospital wards provides one reasonable numerical indicator. In this study poisoned children constituted $5.3 \%$ of the total annual medical admission to this main paediatric hospital. This figure is several times that given for other developing countries ${ }^{6} 711$ but approaches the British ${ }^{12}$ and the American ${ }^{14}$ figures.

In our study and in conformity with most published work $^{89111516}$ truly accidental poisoning is largely confined to the age group 1-5 years. Few cases occurred in children aged under 1 year when the infant's ability to explore is limited by his mobility or after the age of 5, presumably because the child is becoming more discriminative and selective about what he swallows. We consider age and the developmental stage of the child the most important factors in accidental poisoning, as emphasised by Jackson. ${ }^{3}$ During this age impulsive behaviour, curiosity, thoughtlessness, and lack of experience are natural traits. Putting the blame totally on the child's unwillingness to exercise self control or maladjustment ${ }^{17-19}$ is unjustifiable. This view may, however, apply to a few children, ${ }^{12}$ particularly poison repeaters-13\% in this series-and families under stress.

In accord with the findings of other workers ${ }^{814} 15$ there were no sex differences. It is possible that under the age of 5 years the sexes tend to have similar characteristics and behaviour patterns.

Unlike other developing countries where commonly used household products are still the most frequent cause of poisoning ${ }^{811}$ medications are becoming relatively a more important agent in Riyadh. Owing to the affluence of Saudi Arabia, medications as well as household products are becoming increasingly available. The trend is approaching that described in Western countries. ${ }^{8915}$ At any one time an abundance of drugs is found in the Saudi home because drugs can be bought over the counter and people tend to change doctors several times for the same episode of illness. A wide variety of pharmaceutical preparations is, therefore, implicated in contrast to Western countries where salicylates and tranquilisers are highlighted. 891214152021

The range of domestic fluids and substances in Riyadh is also wide. But in this poor section of the community kerosine, which is used for lighting and cooking, is the commonest single cause of poisoning, accounting for $54.9 \%$ of accidents due to domestic products and $25.3 \%$ of the total number of accidents. This percentage is still far less than in other developing countries-and apparently Australia 91122 -but significantly in excess of poisoning by hydrocarbons in Western countries. ${ }^{14}$

Of late the physical environment and the 
availability of and accessibility to poisons in the home have been contested as important factors in the genesis of childhood poisoning. ${ }^{817-2124}$ Stress is not yet a prominent feature of life in this society and children are well loved with conspicuous absence of frustrated child-parent relationships. Some form of stress was recognised in a third of the families in this study, usually due to the mother's temporary unfitness. This is a hazard of town migration because had they remained in their traditional society the extended family system would have helped them. On the contrary, our study in accord with several others $^{3912152526}$ shows that unsafe home environment and poor supervision are the prime epidemiological factors. Even homes of relatives who lead the same life style are not safe. In this study $6 \%$ of poisoning occurred in relative's homes, ${ }^{24} \mathrm{a}$ fact that has also been emphasised by Sibert. ${ }^{13}$

In exploring the epidemiology and prevention of accidental home poisoning in the home it seems imperative to do so in the light of the existing psychosocial, cultural, and environmental factors. This study showed that poisoning occurred almost exclusively in the poorer section of society, who are by and large illiterate and who live in poor overcrowded dwellings. Mothers in this group had little knowledge of the toxicity of drugs and common household substances. Furthermore, they cannot read the labels insisted on by workers in the field. ${ }^{319} 15{ }^{26}$ Culturally they are expected to produce and rear a big family, which is the case in $92 \%$ of families in this survey. The influence of a large number of children in the family has recently been shown in Britain. ${ }^{27}$ With her other domestic duties and a kitchen that is not placed where she can keep an eye on the children at play ${ }^{28}$ the lack of supervision in $95 \%$ of cases is not surprising.

Another cultural trait is the lack of distinction between bedrooms, sitting, and store rooms as the populace prefer to eat, sit, and sleep on carpets on the floor. In this milieu drugs and domestic products are deposited in inappropriate places in almost all cases. Even when they are kept in cabinets or conainers these are not securely locked or covered.

Drugs are usually dispensed in envelopes or plastic topped bottles, from bulk supplies, or easily opened screw top bottles. Most drug containers in Riyadh pharmacies are not childproof; perhaps the safest are those individually wrapped in foil or blister back which delay consumption of large doses. Household products are often transferred to containers that the child associates with a pleasant food or drink, such as soft drink bottles.

There seems to be a universal phenomenon of adult carelessness about drugs in the home even with high standard housing. ${ }^{312426}$ Other studies, with which we do not concur, suggest that careless storage is not a primary cause in poisoning ${ }^{17} 182327$ and those who attempted individual instructions in drug safety and storage met with only limited success. ${ }^{2021}$

The main factors in accidental home poisoning in Riyadh therefore are:

(1) Occurrence at an age when the child cannot be actively taught precautionary methods.

(2) Unfavourable environment where housing is poor, poisonous substances are abundant but not placed in childproof containers, nor stored in appropriate places. Therefore they are extremely available to young children.

(3) Lack of supervision.

(4) Some deeply ingrained cultural characteristics which have a modifying effect and which may take decades to change.

Though no one died in this study 91015 yet morbidity and bed occupancy are high and parents' anxiety considerable. Accidental poisoning is, therefore, an important public health issue that is preventable through a comprehensive approach. Long term preventative measures include improvement of housing and socioeconomic status of the social class affected most. Formal education, raising the horizon of the housewife, and child spacing, since birth control is not practical at the moment, are first steps.

For immediate primary preventive measures we suggest the following:

(1) All drugs and potentially dangerous chemicals should by legislation be sold in childproof containers.? This has proved effective and considerably reduced accidental poisoning in Britain and the United States $^{8} 13151629$

(2) Legislation to reduce the quantity of drugs in the home by banning over the counter selling. The concept of family doctor and health visitor who could act as watch dogs for excess medicine in the homes does not exist in Saudi Arabia.

(3) The question of educating the public through mass media has proved of little value. ${ }^{8183031}$ It is conceded that the section of society we are dealing with is the least likely to be affected by health education through the mass media, which in this case has to be radio and television. Nevertheless, continuous harping on the theme would create public awareness which would in time reach the underprivileged classes. Some success has been achieved by direct and individual counselling by health visitors. ${ }^{20}{ }^{21}$ The same task can be done here through the auspices of female social workers-who exist. Whichever method is used the message should be simple: locking up and diminishing the accessibility of poisonous substances to children and more supervision of those under 5 . The aim is to 
produce a gradual change of parents' behaviour and environment rather than restricting the children's activities.

Domestic and childhood accidents though an important social problem are underdocumented and underresearched in Saudi Arabia. We therefore recommend a national register of accidental poisoning and other accidents, so that the true dimensions of the problem can be fixed, priorities set, and appropriate preventive action taken. A poison information centre(s) would also help the physicians and laymen immensely by giving immediate and detailed advice on the constituents of many household products and unidentified drugs and effective treatments if need be.

\section{References}

${ }^{1}$ Office of Population Censuses and Surveys. Morbidity statistics from general practice. London: HMSO, 1972. (No 36.)

${ }^{2}$ Department of Health and Social Security. Report on presentation of medicine in relation to child safety. London: DHSS, 1974.

${ }^{3}$ Jackson RH. Setting the scene. In: Jackson RH, ed. Children, the environment and accidents. Tunbridge Wells: Pitman Medical, 1977: 1-19.

${ }^{4}$ Whittington C. Accidents in the home. In: Jackson RH, ed. Children, the environment, and accidents. Tunbridge Wells: Pitman Medical, 1977: 66-75.

${ }^{5}$ Office of Population Censuses and Surveys. Mortality statistics childhood and maternity. London: HMSO, 1978;

${ }^{6}$ Manciaux M. Children and accidents. In: Children in the tropics. Paris International Children Centre 1980; 123: 5-35.

${ }^{7}$ Kimati VP. Childhood accidents in Dar Es Salaam. Trop Geogr Med 1977; 2: 91-4.

${ }^{8}$ Craft AW, Sibert JR. Accidental poisoning in children. BR J Hosp Med 1977; 17: 469-78.

${ }^{9}$ Isbister C. Poisoning in childhood, with particular reference to kerosene poisoning. Med J Aust 1963: 2: 652-6.

${ }^{10}$ Reid DHS. Treatment of the poisoned child. Arch Dis Child 1970; 45: 428-32.

${ }^{11}$ Bwido NO. Accidental poisoning in children in Ugandd. Br Med J 1969; iv: 601-2.
${ }^{12}$ Mathew $\mathrm{H}$. Poisoning in the home by medicaments. $\mathrm{Br}$ Med J 1966; ii: 788-90.

${ }^{13}$ Sibert JR. Poisoning in children. Br Med J 1973; i: 803.

${ }^{14}$ Deeths TM, Breeden JT. Poisoning in children-a statistical study of 1057 cases. J Pediatr 1978; 2: 299 305.

${ }^{15}$ Jackson RH, Walker JH, Wynne NA. Circumstances of accidental poisoning in childhood. $\mathrm{Br}$ Med J 1968; iv: 245-8.

${ }^{16}$ Done AK, Jung Al, Wood MC, Klauber MR. Evaluation of safety packings for protection of children. Pediatrics 1971; 48: 613-28.

${ }^{17}$ Sobel R. Traditional safety measures and accidental poisoning in childhood. Pediatrics 1969; 44: 811-6.

${ }^{18}$ Margolis JA. Psychological study of childhood poisoning: a 5-year follow up. Pediatrics 1971; 47: 439-44.

${ }^{19}$ Julyan M, Kuzemko JA. Parents and their children in accidental poisoning. Practitioner 1972; 208: 252-3.

${ }^{20}$ Julyan M, Kuzemko JA. Accidental poisoning in children: the sick family. Practitioner $1975 ; 214: 813-5$.

${ }^{21}$ Baltimore CL, Meyer R. A study of storage, child behavioral traits, and mother's knowledge of toxicology in 52 poisoned families and 52 comparison families. Pediatrics 1968; 42: 312-7.

${ }^{22}$ Baldachin BJ, Melmed RN. Clinical and therapeutic aspects of kerosene poisoning: a series of 200 cases. $\mathrm{Br}$ Med J 1964; ii: 28-30.

${ }^{23}$ Sibert R. Stress in families of children who have ingested poisons. $\mathrm{Br}$ Med J 1975; iii: 87-9.

${ }^{24}$ Graham J. Poisoning in the home. Br Med J 1967; ii: 157-9.

${ }^{25}$ Clements FW, Suathby R, Rowlands JB, Veuthey P. An analysis of deaths from accidental poisoning in children aged under five years. Med J Aust 1963; 2: 649-52.

${ }^{26}$ Basavaraj DS, Foster DP. Accidental poisoning in children.J Epidemiol Community Health 1982, 36: 314.

${ }^{27}$ Sinnott WR. Safety aspects of domestic architecture. In: Jackson RH, ed. Children, the environment and accidents. Tunbridge Wells: Pitman Medical, 1977: 91101.

${ }^{28}$ Scherz RG, Latham GH, Stracener CE. Child resistant containers can prevent poisoning. Pediatrics 1971; 48: 613-27.

${ }^{29}$ Calnan MW, Dale JW, de Fonseka CP. Suspected poisoning in children. Arch Dis Child 1976; 51: 1805.

${ }^{30}$ Clover AF, Hutchinson PJ, Judson EC. Promoting children's home safety. Br Med J 1982; 285; 1177-80.

${ }^{31}$ Kirk NS. Design aspects of product safety. In: Jackson $\mathrm{RH}$, ed. Children, the environment and accidents. Tunbridge Wells: Pitman Medical 1977: 91-101. 